Article

\title{
Potential Refinement of Recurrence Score by pSTAT3 Status
}

\author{
Albert Grinshpun ${ }^{1,2,+} \oplus$, Yogev Cohen ${ }^{1,2,+} \oplus$, Aviad Zick ${ }^{1,2}{ }^{\oplus}$, Luna Kadouri ${ }^{1,2}$, Tamar Hamburger ${ }^{1}$, Benjamin Nisman ${ }^{1}$, \\ Tanir M. Allweis ${ }^{2,3}$, Gabriela Oprea ${ }^{4}$, Tamar Peretz ${ }^{1,2}$, Beatrice Uziely ${ }^{1,2}$ and Amir Sonnenblick ${ }^{5, *}$ \\ 1 Sharett Institute of Oncology, Hadassah-Hebrew University Medical Center, Jerusalem 91120, Israel; \\ albert.grinshpun@mail.huji.ac.il (A.G.); yogev.cohen@mail.huji.ac.il (Y.C.); aviadz@hadassah.org.il (A.Z.); \\ luna@hadassah.org.il (L.K.); tamarh@hadassah.org.il (T.H.); nisman@hadassah.org.il (B.N.); \\ tamary@hadassah.org.il (T.P.); beatrice@hadassah.org.il (B.U.) \\ 2 Faculty of Medicine, The Hebrew University, Jerusalem 9112102, Israel; tanir@hadassah.org.il \\ 3 Department of Surgery, Hadassah-Hebrew University Medical Center, Jerusalem 91120, Israel \\ 4 Department of pathology, Emory University, Atlanta, GA 30322, USA; goprea@emory.edu \\ 5 Institute of Oncology, Tel Aviv Sourasky Medical Center, Tel Aviv, Israel and Sackler Faculty of Medicine, \\ Tel Aviv University, Tel Aviv 6423906, Israel \\ * Correspondence: amirson@tlvmc.gov.il; Tel.: +972-3-6972061; Fax: +972-3-6974789 \\ + These authors contributed equally to this work.
}

Citation: Grinshpun, A.; Cohen, Y.; Zick, A.; Kadouri, L.; Hamburger, T.; Nisman, B.; Allweis, T.M.; Oprea, G.; Peretz, T.; Uziely, B.; et al. Potential Refinement of Recurrence Score by pSTAT3 Status. Genes 2022, 13, 438. https://doi.org/10.3390/ genes13030438

Academic Editor: Stefania Bortoluzzi

Received: 1 February 2022

Accepted: 25 February 2022

Published: 27 February 2022

Publisher's Note: MDPI stays neutral with regard to jurisdictional claims in published maps and institutional affiliations.

Copyright: (C) 2022 by the authors. Licensee MDPI, Basel, Switzerland. This article is an open access article distributed under the terms and conditions of the Creative Commons Attribution (CC BY) license (https:// creativecommons.org/licenses/by/ $4.0 /)$

\begin{abstract}
The likelihood of recurrence in breast cancer patients with hormone receptor-positive (HR-positive) tumors is influenced by clinical, histopathological, and molecular features. Recent studies suggested that activated STAT3 (pSTAT3) might serve as a biomarker of outcome in breast cancer patients. In the present work, we have analyzed the added value of pSTAT3 to OncotypeDx Recurrence Score (RS) in patient prognostication. We have found that patients with low RS $(<26)$ and low pSTAT3 might represent a population at a higher risk for cancer recurrence. Furthermore, we have observed that a positive pSTAT3 score alone can be a favorable marker for patients with HR-positive breast cancer under the age of 50. In an era of personalized medicine, these findings warrant further appraisal of chemotherapy benefit in this population.
\end{abstract}

Keywords: early breast cancer; recurrence score; oncotype; pSTAT3; prognosis

\section{Introduction}

Recent advances in the field of personalized medicine have deepened our understanding of how to integrate clinical parameters with molecular tools to prognosticate patients. When looking into clinical management of early breast cancer, routine use of molecular assay such as OncotypeDX Breast Recurrence Score (RS) has revolutionized clinical practice and helps clinicians to assess the risk of relapse and the need, if necessary, for systemic adjuvant therapies $[1,2]$.

Yet, molecular tools are not perfect, and their accuracy is a matter of debate [3]. Therefore, multiple additional tools are being studied to aid the prognostication process and provide clinically relevant information of the benefit of adjuvant chemotherapy [4-6].

Janus Kinases (JAKs) and their downstream signal transducers and activators of transcription (STAT) proteins are heavily involved in malignant processes. Specifically, STAT3 was found to be crucial for tumor progression through different mechanisms that include direct effects on proliferation, angiogenesis, apoptosis, and survival, as well as having a non-direct effect on the immune and stromal environment surrounding the tumor [7-11].

In patients with breast cancer, STAT3 has several key roles in tumor development and progression, as shown by numerous studies $[4,7,8,12-14]$. Previously, we and others have shown the prognostic and predictive roles of phospho-STAT3 (pSTAT3) in breast cancer, mainly in luminal tumors $[4,5,12-16]$.

In the current preliminary work, we sought to determine whether pSTAT3 can add additional prognostic information to RS results and guide better clinical decision making. 


\section{Methods}

\subsection{Tissue Analysis:}

Formalin fixed, paraffin-embedded invasive breast cancer tissues from hormone receptor (HR) positive, HER2-negative, early breast carcinoma patients treated between the years 1996-2013 were available from the Department of Pathology.

Tissue cores with a diameter of $0.6 \mathrm{~mm}$ were taken with a manual tissue array maker MTA-1 (Beecher Instruments) arrayed in duplicates or triplicates on a recipient paraffin block and placed on charged poly-lysine-coated slides [12].

The immunodetection and scoring of pSTAT3 was carried out as previously described, and the staining was determined according to the the Remmele score $(0-6$, intensity + percentage, intensity ( 0 , negative; 1 , weak; 2 , moderate; 3 , strong) + percentage of the stained tumor cells $(0,<10 \% ; 1,10-25 \% ; 2,25-50 \%$ and $3,50-100 \%))$ [12].

Nuclear Phospho-STAT3 staining was determined separately for each specimen (Figure 1).

(a)

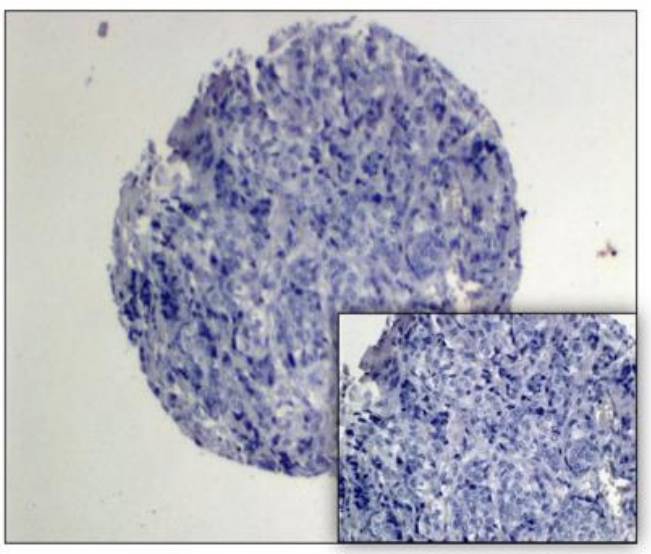

(b)

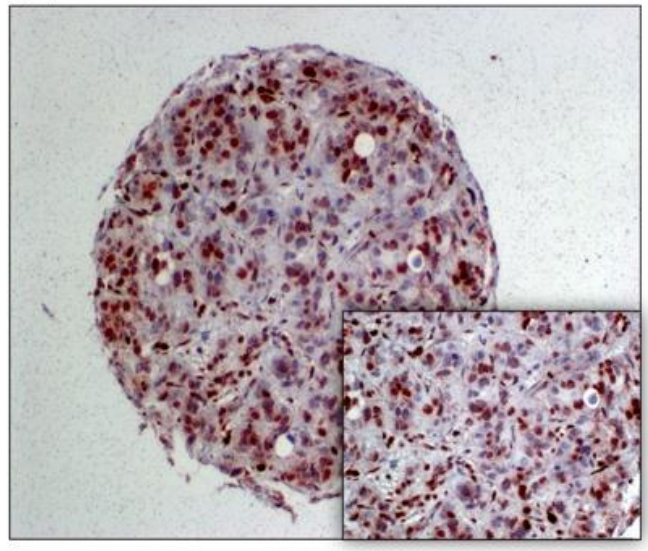

Figure 1. pSTAT3 expression, breast cancer tissue microarray sports as follows: (a) pSTAT3 negative, (b) pSTAT3 strongly positive.

Positive pSTAT3 IHC was defined as score $\geq 2$.

\subsection{Clinical Data}

Demographic, clinical, and recurrence data were obtained from electronic medical records. The use of tumor specimens and data in this research was approved by the Medical Ethics Committee of the Hadassah Medical Center, and each patient gave written informed consent.

\subsection{Statistical Analysis}

The statistical analysis was generated using SPSS software version 27. Chi-square test for categorical data and unpaired Student's t-test for continuous variables were used. Estimated DFS and overall survival (OS) rates according to the pSTAT3 score subgroups were calculated by the product limit method (Kaplan-Meier) for all patients and were stratified by age at diagnosis; 95\% confidence intervals (CIs) were calculated from the model. Multivariate models were computed with Cox proportional-hazards regression.

$p$ values $\leq 0.05$ were considered statistically significant.

\section{Results}

The study population comprised of 449 women with interpretable pSTAT3 IHC. The median age at diagnosis was 52. A comparison between pSTAT3 positive versus pSTAT3 negative tumors did not demonstrate a significant relationship between pSTAT3 positivity and age, histological grade, tumor size, histological type, and involved lymph node number $(p>0.05)$. Furthermore, we have analyzed the relation between pSTAT3 status and survival 
in 436 patients with known outcome. The median follow up was 105 months (censored at 10 years of follow up). In pSTAT3-positive tumors, the 10-year overall survival was non-significantly greater than pSTAT3 negative tumors (78.1\% vs. 69.4\%, $p=0.17)$. A multivariate analysis adjusted for stage, age, and grade did not demonstrate an association of pSTAT3 with overall survival (hazard ratio for death, 0.72 (95\% CI, 0.41-1.28); $p=0.26$ ).

To obtain additional insight into the role of pSTAT3 in prognostication, we have analyzed a subset of 75 patients with known RS results (Table 1). Of them, 16 patients $(21.3 \%)$ had breast cancer recurrence, and one patient suffered from metastatic second primary tumor (lung cancer). The median age on primary diagnosis was 70.15. The median follow-up time was 114 months.

Table 1. Patient characteristics according to pSTAT3 Score.

\begin{tabular}{|c|c|c|c|c|c|c|}
\hline \multirow{3}{*}{$\begin{array}{c}\text { Variable } \\
\text { Sub-Variable }\end{array}$} & & \multicolumn{4}{|c|}{$\begin{array}{c}\text { pSTAT3 Score, Negative }(<2) / \text { Positive }(\geq 2) \\
n=75\end{array}$} & \multirow{3}{*}{$p$ Value } \\
\hline & & \multicolumn{2}{|c|}{ Negative } & \multicolumn{2}{|c|}{ Positive } & \\
\hline & & $(n=49)$ & $\mathrm{n} \%$ & $(n=26)$ & $\mathbf{n} \%$ & \\
\hline \multirow{2}{*}{ Age at diagnosis } & Over 50 & 38 & $77.6 \%$ & 18 & $69.2 \%$ & \multirow{2}{*}{0.43} \\
\hline & Under 50 & 11 & $22.4 \%$ & 8 & $30.8 \%$ & \\
\hline \multirow{4}{*}{ Tumor type } & Ductal & 35 & $71.4 \%$ & 17 & $65.4 \%$ & \multirow{4}{*}{0.966} \\
\hline & Lobular & 5 & $10.2 \%$ & 3 & $11.5 \%$ & \\
\hline & Mucinous & 1 & $2.0 \%$ & 1 & $3.8 \%$ & \\
\hline & Both Ductal and Lobular & 8 & $16.3 \%$ & 5 & $19.2 \%$ & \\
\hline \multirow{2}{*}{ Lymph Nodes } & No & 38 & $77.6 \%$ & 20 & $76.9 \%$ & \multirow{2}{*}{0.951} \\
\hline & Yes & 11 & $22.4 \%$ & 6 & $23.1 \%$ & \\
\hline \multirow{2}{*}{ Chemotherapy } & No & 33 & $67.3 \%$ & 20 & $76.9 \%$ & \multirow{2}{*}{0.357} \\
\hline & Yes & 16 & $32.7 \%$ & 6 & $23.1 \%$ & \\
\hline \multirow{2}{*}{ Hormone therapy } & No & 6 & $12.2 \%$ & 2 & $7.7 \%$ & \multirow{2}{*}{0.706} \\
\hline & Yes & 43 & $87.8 \%$ & 24 & $92.3 \%$ & \\
\hline \multirow{2}{*}{ RS score } & $\leq 26$ & 41 & $83.7 \%$ & 25 & $96.2 \%$ & \multirow{2}{*}{0.15} \\
\hline & $>26$ & 8 & $10.3 \%$ & 1 & $3.8 \%$ & \\
\hline \multirow{2}{*}{ Recurrence } & No & 34 & $69.4 \%$ & 25 & $96.2 \%$ & \multirow{2}{*}{0.007} \\
\hline & Yes & 15 & $30.6 \%$ & 1 & $3.8 \%$ & \\
\hline \multirow{2}{*}{ Age } & Median (range) & \multirow{2}{*}{\multicolumn{2}{|c|}{$\begin{array}{c}61.39(29.7-81) \\
58.01 \pm 12.07\end{array}$}} & \multirow{2}{*}{\multicolumn{2}{|c|}{$\begin{array}{c}57.91(38.6-77.9) \\
57.88 \pm 10.68\end{array}$}} & \multirow[b]{2}{*}{0.963} \\
\hline & Mean \pm SD & & & & & \\
\hline
\end{tabular}

Nine patients (12\%) had a high RS of 26 or more. Additionally, $36 \%$ of patients had positive pSTAT3 scores $(\geq 2)$. It is noteworthy that patients in low and high RS groups $(\leq 25$, 26 and more, respectively) had similar characteristics in regard with age, tumor grade, histological type, tumor size, and lymph node number.

When patients were divided according to their pSTAT3 IHC scores (Figure 2a), we observed that positive scores were significantly associated with a reduced risk of recurrence ( $p=0.005)$; out of the 16 patients that had disease recurrence, only one was positive for pSTAT3.

Additionally, patients' allocation with negative pSTAT3 scores $(<2)$ to high or low RS (with a cutoff of 26) showed that both groups have similar percentage of recurrence.

On the other hand, when patient allocation started according to RS scores (Figure $2 b$ ) and then we dichotomized according to positive or negative pSTAT3, the low RS $\backslash$ high pSTAT3 group had a significantly better prognosis $(p=0.007)$.

DFS analysis according to the pSTAT3 score did not show a statistically significant difference between the 'negative' groups and the 'positive' group (Figure $3 a, p=0.109$ ). Yet, DFS analysis according to the pSTAT3 score showed a statistically significant difference between the 'negative' groups and the 'positive' group when adjusted by age at diagnosis (Figure $3 b, p=0.03$ ). 

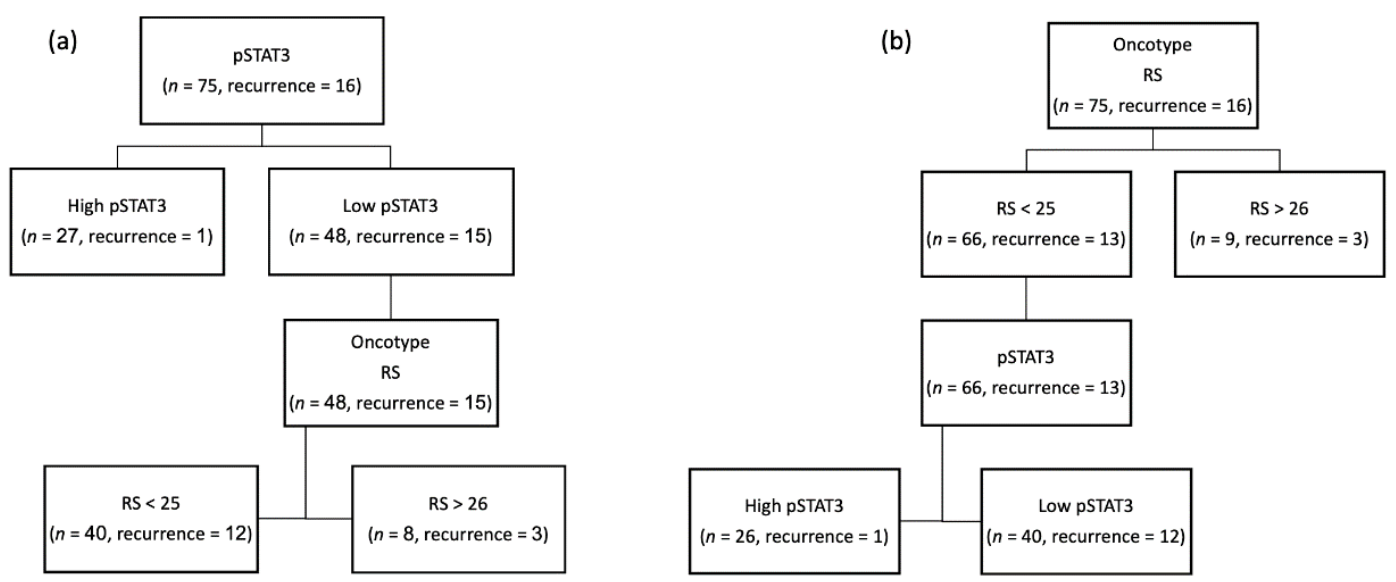

Figure 2. (a) Patients divided according to their pSTAT3 IHC scores; (b) patient allocation started according to RS scores.

(a)

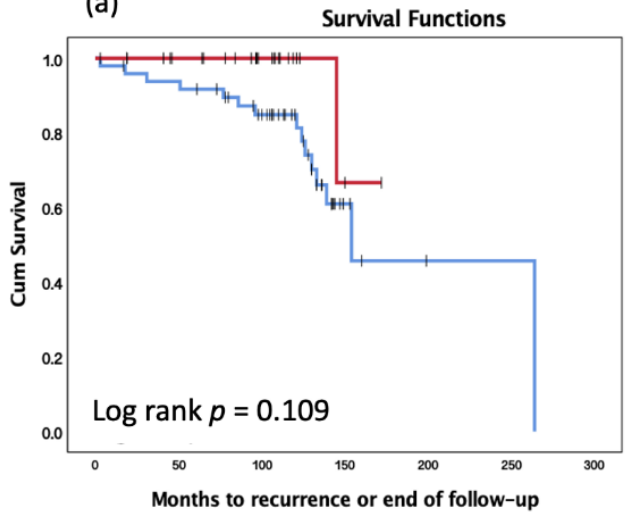

(b)

Survival Functions Adjusted by age at diagnosis Under 50

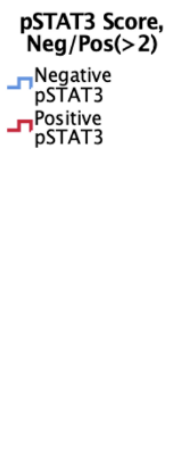

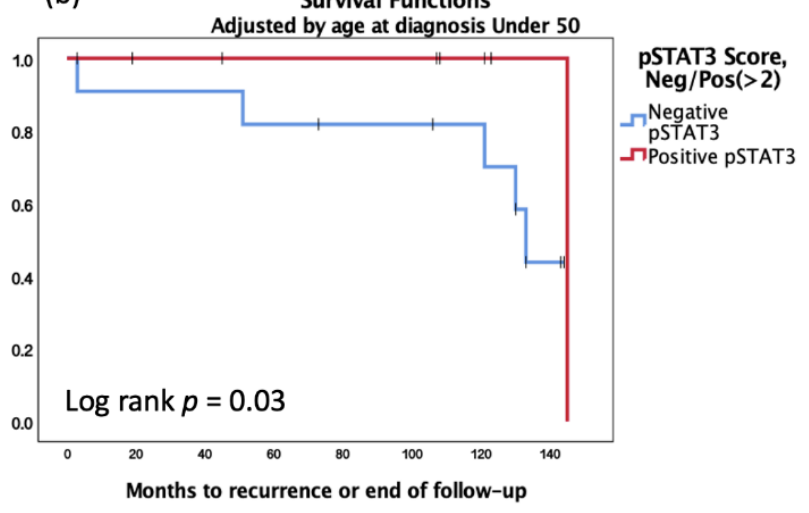

Figure 3. Kaplan-Meier analysis for DFS (a) according to the pSTAT3; (b) according to the pSTAT3 and adjusted by age at diagnosis.

Multivariate analysis of the clinical and pathological data for DFS was preformed (Table 2). We found that several clinical and pathological characteristics were associated with worse DFS, including age under 50 at diagnosis $(p=0.039)$ and Lobular type $(p=0.024)$.

Table 2. Multivariate analysis for DFS.

\begin{tabular}{|c|c|c|c|c|}
\hline \multicolumn{5}{|c|}{ Multivariate Analysis of the Clinical and Pathological Data for DFS } \\
\hline & \multirow{2}{*}{ Adjusted HR } & \multicolumn{2}{|c|}{$95.0 \%$ CI for HR } & \multirow{2}{*}{$p$ Value } \\
\hline & & Lower & Upper & \\
\hline RS score, Neg/Pos (>26) & 0.548 & 0.089 & 3.394 & 0.518 \\
\hline Lymph Nodes & 2.709 & 0.405 & 18.119 & 0.304 \\
\hline Type: Ductal/Lobular/Mucinous/Ductal \& Lobular & & & & 0.024 \\
\hline Type: Ductal vs. Lobular & 14.367 & 1.261 & 163.673 & 0.032 \\
\hline Type: Ductal vs. Mucinous & 39.831 & 2.747 & 577.569 & 0.007 \\
\hline Type: Ductal vs. Ductal and Lobular & 3.839 & 0.893 & 16.502 & 0.071 \\
\hline Chemotherapy & 0.556 & 0.118 & 2.623 & 0.458 \\
\hline Hormone therapy & 1.946 & 0.302 & 12.532 & 0.483 \\
\hline Tumor Size (cm) & 0.981 & 0.438 & 2.198 & 0.963 \\
\hline pSTAT3 Score, Negative/Positive $(\geq 2)$ & 5.462 & 0.584 & 51.121 & 0.137 \\
\hline Age at diagnosis under 50 & 5.778 & 1.092 & 30.560 & 0.039 \\
\hline
\end{tabular}

The hazard ratio of RS score $(<26 />26)$ is $0.548(p=0.518)$, and the hazard ratio of pSTAT3 score is $5.462(p=0.137)$. 


\section{Discussion}

In our preliminary analysis, we have partially recapitulated the known association between positive pSTAT3 to better prognosis and found that pSTAT3 scores might potentially add valuable prognostic data to RS in assessing patients' risk of early, HR-positive breast cancer recurrence.

As STAT3 functions as a key player in numerous pro-tumorigenic processes, one may expect that its activation will be associated with poor prognosis. However, the reality is far more complex, as shown in previous publications on PSTAT3 as being both a poor and improved prognosis biomarker. Interestingly, this phenomenon was also shown in other tumor types, such as STAT3 contradictory roles in non-small lung cancer [17].

STAT3, as was mentioned, has been shown to play key roles in the cell's cycle and is mostly considered growth promoting and an antiapoptotic factor. In normal conditions, STAT3 activation is terminated by suppressors of cytokine signaling proteins.

However, cancer cells exhibit constitutively activated STAT3, which is attributable to upregulated tyrosine kinases and the deregulation of its negative regulation by suppressors of cytokine signaling proteins.

STAT3 activation and its target genes in the cell stimulate growth, angiogenesis, and cell motility and inhibit apoptosis. In addition to cell survival and proliferation, STATs regulate several other biological processes that may contribute to cancer. STAT3 has been shown to promote angiogenesis and may contribute to cancer by allowing tumors to evade detection by the host immune system

One of the important cytokines in this mechanism is interleukin-6 (IL6).

IL6, binding to its receptor complex IL6R/gp130, activates downstream Janus kinases, which subsequently activate the signal transducer and activator of STAT3 through phosphorylation.

Interestingly, IL6/STAT3 signaling has been shown to play a role in tumor progression by inducing epithelial to mesenchymal transition and angiogenesis. In breast cancer, STAT3 is most often activated by IL6 [18].

In fact, many breast cancer cell lines produce IL6, which activates STAT3 by signaling through the IL-6 receptor and Jak kinases [18,19].

One would expect that tumors that express constitutive phospho-STAT3 expression would be associated with poorer prognosis, but our results show otherwise.

In order to resolve this seemingly troublesome inconsistency, we theorized that in clinic, pSTAT3 has a predictive role for adjuvant chemotherapy benefit in breast cancer patients.

Dien et al. found a trend, although the results were not statistically significant for longer survival in patients with increased STAT3 activation, and hypothesized that pSTAT3 regulates Tissue Inhibitor of Metalloproteinase-1 (TIMP1), which makes breast cancer cells less invasive [20].

Furthermore, other studies showed that STAT3 is a tumor suppressor protein with a role in breast tissue cellular differentiation and apoptosis [21,22].

Couto et al. found that siRNA knockdown of STAT3 resulted in significantly increased tumor growth in thyroid cancer cell lines. This study also found a correlation between the STAT3 knockdown and increased glucose uptake and the production of lactate in the cell lines. Those finding suggest that one of the mechanisms of the tumorigenesis inhibition character of STAT3 is mediated by inhibiting aerobic glycolysis [23].

Finally, Lee et al. found that STAT3 mediates tumor suppressor effects by binding to GSK3 $\beta$, which, in turn, promotes the phosphorylation and the degradation of Snail, a critical regulator of the EMT and cancer metastasis [24].

Evidence that STAT3 plays a role in cellular differentiation and apoptosis, functions as a tumor suppressor, and regulates the in-cell process that decreases cancer cell invasiveness may be consistent with better outcomes in breast cancer patients with high pSTAT3.

A possible explanation for our findings can be drawn from a recent computational analysis of pSTAT3 phenotype [5]. In that work, researchers have shown that patients in the luminal A population were much more likely to possess a pSTAT3 high phenotype, whereas those in the luminal B population were much more likely to have a pSTAT3 low phenotype. 


\section{Conclusions}

In modern oncology, clinicians' decisions on adjuvant chemotherapy are complex and based on a variety of factors: clinical, pathologic, and molecular. Yet, much room for improvement and personalization exists. In the present trial, we correlate pSTAT3 to RS and identify another and novel potential population (low RS $\backslash$ low pSTAT3) that might benefit from chemotherapy despite low RS (<26). Furthermore, pSTAT3 immunohistochemistry as a simple stand-alone test may possibly also provide prognostic data [4,5,25-27].

Taken together, our observations imply that a double-low score (low RS $\backslash$ low pSTAT3) is a marker of unfavorable outcome in HR-positive breast cancer, mainly in patients under the age of 50 on primary diagnosis. If confirmed in a larger-designed prospective randomized trial, our findings would indicate that PSTAT3 testing could be used as an adjunct biomarker to direct rational adjuvant treatment in luminal breast cancer patients.

Author Contributions: Conceptualization, A.G., T.P. and A.S.; data curation, T.H., B.N. and T.P.; formal analysis, A.G., Y.C., A.Z., L.K., T.P. and A.S.; funding acquisition, A.S.; investigation, L.K., T.M.A., G.O., T.P., B.U. and A.S.; methodology, G.O., B.U. and A.S.; project administration, T.H.; supervision, T.P. and A.S.; visualization, G.O.; writing-original draft, A.G., Y.C. and A.S., writingreview and editing, A.G., Y.C., A.Z., T.P. and A.S. All authors have read and agreed to the published version of the manuscript.

Funding: This study was funded by a Clinical Research Career Development Award from the Israel Cancer Research Fund grants (16-116-CRCDA), the Israeli Cancer Research Association, and the Raymond F. Schinazi International program.

Institutional Review Board Statement: The study was conducted according to the guidelines of the Declaration of Helsinki, and approved by the Institutional Review Board of Hadassah Medical Center (014-0366, September 2015).

Informed Consent Statement: Informed consent was obtained from all subjects involved in the study.

Data Availability Statement: The data presented in this study are available on request from the corresponding author.

Acknowledgments: The authors would like to thank Tali Bdolah-Abram from the Hebrew University of Jerusalem for her help with the statistical analysis. The study was conducted as part of the requirements for YC's M.D. certificate in the Faculty of Medicine, the Hebrew University of Jerusalem.

Conflicts of Interest: The authors declare no conflict of interest.

\section{References}

1. Sparano, J.A.; Gray, R.J.; Makower, D.F.; Pritchard, K.I.; Albain, K.S.; Hayes, D.F.; Geyer, C.E., Jr.; Dees, E.C.; Goetz, M.P.; Olson, J.A.; et al. Adjuvant Chemotherapy Guided by a 21-Gene Expression Assay in Breast Cancer. N. Engl. J. Med. 2018, 379, 111-121. [CrossRef] [PubMed]

2. Carlson, J.J.; Roth, J.A. The impact of the Oncotype Dx breast cancer assay in clinical practice: A systematic review and meta-analysis. Breast Cancer Res. Treat. 2013, 141, 13-22. [CrossRef]

3. Tiberi, D.; Masucci, L.; Shedid, D.; Roy, I.; Vu, T.; Patocskai, E.; Robidoux, A.; Wong, P. Limitations of Personalized Medicine and Gene Assays for Breast Cancer. Cureus 2017, 9, e1100. [CrossRef] [PubMed]

4. Sonnenblick, A.; Uziely, B.; Nechushtan, H.; Kadouri, L.; Galun, E.; Axelrod, J.H.; Katz, D.; Daum, H.; Hamburger, T.; Maly, B.; et al. Tumor STAT3 tyrosine phosphorylation status, as a predictor of benefit from adjuvant chemotherapy for breast cancer. Breast Cancer Res. Treat. 2013, 138, 407-413. [CrossRef] [PubMed]

5. Sonnenblick, A.; Salgado, R.; Brohée, S.; Zahavi, T.; Peretz, T.; Eynden, G.V.D.; Rouas, G.; Salmon, A.; Francis, P.A.; Di Leo, A.; et al. p-STAT3 in luminal breast cancer: Integrated RNA-protein pooled analysis and results from the BIG 2-98 phase III trial. Int. J. Oncol. 2017, 52, 424-432. [CrossRef]

6. Zhao, Y.; Schaafsma, E.; Cheng, C. Gene signature-based prediction of triple-negative breast cancer patient response to Neoadjuvant chemotherapy. Cancer Med. 2020, 9, 6281-6295. [CrossRef]

7. Niu, G.; Wright, K.L.; Huang, M.; Song, L.; Haura, E.; Turkson, J.; Zhang, S.; Wang, T.; Sinibaldi, D.; Coppola, D.; et al. Constitutive Stat3 activity up-regulates VEGF expression and tumor angiogenesis. Oncogene 2002, 21, 2000-2008. [CrossRef]

8. Garcia, R.; Bowman, T.L.; Niu, G.; Yu, H.; Minton, S.; Muro-Cacho, C.A.; Cox, C.E.; Falcone, R.; Fairclough, R.; Parsons, S.; et al. Constitutive activation of Stat 3 by the Src and JAK tyrosine kinases participates in growth regulation of human breast carcinoma cells. Oncogene 2001, 20, 2499-2513. [CrossRef] [PubMed] 
9. Yu, H.; Lee, H.; Herrmann, A.; Buettner, R.; Jove, R. Revisiting STAT3 signalling in cancer: New and unexpected biological functions. Nat. Cancer 2014, 14, 736-746. [CrossRef]

10. Knüpfer, H.; Preiß, R. Significance of interleukin-6 (IL-6) in breast cancer (review). Breast Cancer Res. Treat. 2006, 102, 129-135 [CrossRef]

11. Yu, H.; Pardoll, D.; Jove, R. STATs in cancer inflammation and immunity: A leading role for STAT3. Nat. Cancer 2009, 9, 798-809. [CrossRef] [PubMed]

12. Sonnenblick, A.; Shriki, A.; Galun, E.; Axelrod, J.H.; Daum, H.; Rottenberg, Y.; Hamburger, T.; Mali, B.; Peretz, T. Tissue microarray-based study of patients with lymph node-positive breast cancer shows tyrosine phosphorylation of signal transducer and activator of transcription 3 (tyrosine705-STAT3) is a marker of good prognosis. Clin. Transl. Oncol. 2012, 14, 232-236. [CrossRef] [PubMed]

13. Walker, S.R.; Nelson, E.A.; Yeh, J.E.; Pinello, L.; Yuan, G.-C.; Frank, D.A. STAT5 Outcompetes STAT3 to Regulate the Expression of the Oncogenic Transcriptional Modulator BCL6. Mol. Cell. Biol. 2013, 33, 2879-2890. [CrossRef]

14. Dolled-Filhart, M.; Camp, R.L.; Kowalski, D.P.; Smith, B.L.; Rimm, D.L. Tissue Microarray Analysis of Signal Transducers and Activators of Transcription 3 (Stat3) and Phospho-Stat3 (Tyr705) in Node-negative Breast Cancer Shows Nuclear Localization Is Associated with a Better Prognosis. Clin. Cancer Res. 2003, 9, 594-600. [PubMed]

15. Walker, S.R.; Xiang, M.; Frank, D.A. Distinct roles of STAT3 and STAT5 in the pathogenesis and targeted therapy of breast cancer. Mol. Cell. Endocrinol. 2014, 382, 616-621. [CrossRef]

16. Sonnenblick, A.; Brohée, S.; Fumagalli, D.; Vincent, D.; Venet, D.; Ignatiadis, M.; Salgado, R.; Eynden, G.V.D.; Rothé, F.; Desmedt, C.; et al. Constitutive phosphorylated STAT3-associated gene signature is predictive for trastuzumab resistance in primary HER2-positive breast cancer. BMC Med. 2015, 13, 177. [CrossRef] [PubMed]

17. Mohrherr, J.; Uras, I.Z.; Moll, H.P.; Casanova, E. STAT3: Versatile Functions in Non-Small Cell Lung Cancer. Cancers 2020, $12,1107$. [CrossRef]

18. Lieblein, J.C.; Ball, S.; Hutzen, B.; Sasser, A.K.; Lin, H.-J.; Huang, T.H.; Hall, B.M.; Lin, J. STAT3 can be activated through paracrine signaling in breast epithelial cells. BMC Cancer 2008, 8, 302-314. [CrossRef]

19. Marotta, L.L.; Almendro, V.; Marusyk, A.; Shipitsin, M.; Schemme, J.; Walker, S.R.; Bloushtain-Qimron, N.; Kim, J.J.; Choudhury, S.A.; Maruyama, R.; et al. The JAK2/STAT3 signaling pathway is required for growth of CD $44^{+} \mathrm{CD} 24^{-}$stem cell-like breast cancer cells in human tumors. J. Clin. Investig. 2011, 121, 2723-2735. [CrossRef]

20. Dien, J.; Amin, H.M.; Chiu, N.; Wong, W.; Frantz, C.; Chiu, B.; Mackey, J.R.; Lai, R. Signal Transducers and Activators of Transcription-3 Up-Regulates Tissue Inhibitor of Metalloproteinase-1 Expression and Decreases Invasiveness of Breast Cancer. Am. J. Pathol. 2006, 169, 633-642. [CrossRef]

21. Chapman, R.S.; Lourenco, P.C.; Tonner, E.; Flint, D.J.; Selbert, S.; Takeda, K.; Akira, S.; Clarke, A.; Watson, C.J. Suppression of epithelial apoptosis and delayed mammary gland involution in mice with a conditional knockout of Stat3. Genes Dev. 1999, 13, 2604-2616. [CrossRef]

22. Sarosiek, K.A.; Malumbres, R.; Nechushtan, H.; Gentles, A.J.; Avisar, E.; Lossos, I.S. Novel IL-21 signaling pathway up-regulates c-Myc and induces apoptosis of diffuse large B-cell lymphomas. Blood 2010, 115, 570-580. [CrossRef]

23. Couto, J.P.; Daly, L.; Almeida, A.; Knauf, J.A.; Fagin, J.A.; Sobrinho-Simoes, M.; Lima, J.; Maximo, V.; Soares, P.; Lyden, D.; et al. STAT3 negatively regulates thyroid tumorigenesis. Proc. Natl. Acad. Sci. 2012, 109, E2361-E2370. [CrossRef] [PubMed]

24. Lee, J.; Kim, J.C.K.; Lee, S.-E.; Quinley, C.; Kim, H.R.; Herdman, S.; Corr, M.; Raz, E. Signal Transducer and Activator of Transcription 3 (STAT3) Protein Suppresses Adenoma-to-carcinoma Transition in Apcmin ${ }^{\text {/+ }}$ Mice via Regulation of Snail-1 (SNAI) Protein Stability. J. Biol. Chem. 2012, 287, 18182-18189. [CrossRef]

25. Liu, Y.; Huang, J.; Li, W.; Chen, Y.; Liu, X.; Wang, J. Meta-analysis of STAT3 and phospho-STAT3 expression and survival of patients with breast cancer. Oncotarget 2018, 9, 13060-13067. [CrossRef] [PubMed]

26. Segatto, I.; Baldassarre, G.; Belletti, B. STAT3 in Breast Cancer Onset and Progression: A Matter of Time and Context. Int. J. Mol. Sci. 2018, 19, 2818. [CrossRef]

27. Wu, P.; Wu, D.; Zhao, L.; Huang, L.; Shen, G.; Chai, Y. Prognostic role of STAT3 in solid tumors: A systematic review and meta-analysis. Oncotarget 2016, 7, 19863-19883. [CrossRef] [PubMed] 